\title{
Using Etomidate in a Two-month-old Infant with Cushing Syndrome due to Adrenocortical Carcinoma
}

\author{
(D) Ahreum Kwon ${ }^{1}$, (D) Yongha Choi ${ }^{1}$, (D) Jo Won Jung2 , (D) Junghwan Suh ${ }^{1}$, (D) Ho-Seong Kim ${ }^{1}$ \\ ${ }_{1}^{1}$ Division of Pediatric Endocrinology, Severance Children's Hospital, Department of Pediatrics, Institute of Endocrinology, Yonsei University \\ College of Medicine, Seoul, Korea \\ 2Division of Pediatric Cardiology, Severance Hospital, Department of Pediatrics, Yonsei University College of Medicine, Seoul, Korea
}

\begin{abstract}
What is already known on this topic?
Medical treatment of Cushing syndrome (CS) is important, particularly when a surgical cure is impossible. Although etomidate is an adrenal-blocking drug used to treat CS, its use in infants is unreported.
\end{abstract}

\section{What this study adds?}

Here we describe the case of a 2-month-old girl treated with etomidate for CS caused by adrenocortical carcinoma. We identified a safe dosage with an infusion rate of $0.03 \mathrm{mg} / \mathrm{kg} / \mathrm{hour}$, and observed good control of hypercortisolemia after treatment.

\begin{abstract}
Cushing syndrome (CS) is a rare disease caused by hypercortisolemia. Although surgical treatment is the first-line treatment in CS, the appropriate medication for the patient's condition should be selected when medical treatment is needed. Etomidate is an adrenal-blocking drug used to treat CS and the most suitable for severe hypercortisolemia and adrenocortical carcinoma (ACC), due to cardiovascular stability and an anti-tumorigenic effect. However, its use and safe recommended dosage in infants with CS is unreported. Here we describe the case of a 2-month-old girl treated with etomidate for CS caused by ACC. Even though radical mass excision was performed, severe hypercortisolemia persisted, resulting from metastatic lesions in the liver, and medical treatment was considered. The etomidate doses, no bolus dose and infusion rate of $0.03 \mathrm{mg} / \mathrm{kg} /$ hour, may be an appropriate dose for severe hypercortisolemia in infants. This case will help determine future treatment strategies for similar cases in infants.
\end{abstract}

Keywords: Etomidate, infant, Cushing syndrome

\section{Introduction}

Cushing syndrome (CS) is a rare disease, particularly in children (1). First-line treatment of CS is surgical resection of the source of excess glucocorticoid. However, non-surgical medical treatment of hypercortisolemia is important when the mass is unresectable, or in pre-and postoperative emergency situations. Reports of non-surgical medical treatment of CS in infants are very rare.

Medical treatment for CS can be divided into three groups: adrenal-blocking drugs; neuromodulatory drugs; and glucocorticoid receptor-blocking agents (2). Among these, adrenal-blocking drugs are based on inhibition of adrenal steroidogenesis at enzymatic sites, with the most frequently used drugs being oral ketoconazole and metyrapone. Ketoconazole inhibits multiple enzymes involved in adrenal steroidogenesis, but can cause hepatotoxicity (2). Metyrapone blocks the last step of cortisol synthesis, increasing the concentration of several precursor molecules with mineralocorticoid activity. Therefore, metyrapone may cause hypertension, edema, or hypokalemia (2).

Etomidate is an adrenal-blocking drug that functions by inhibiting enzymes in adrenal steroidogenesis. It exhibits a rapid onset of action, does not dramatically change blood
Address for Correspondence: Ahreum Kwon MD, Division of Pediatric Endocrinology, Severance Children's Hospital, Department of Pediatrics, Institute of Endocrinology, Yonsei University College of Medicine, Seoul, Korea

Phone: + 82-2-2228-8203 E-mail: armea@yuhs.ac ORCID: orcid.org/0000-0002-9692-2135

${ }^{\circ}$ Copyright 2022 by Turkish Pediatric Endocrinology and Diabetes Society

The Journal of Clinical Research in Pediatric Endocrinology published by Galenos Publishing House.
Conflict of interest: None declared Received: 14.07 .2020 Accepted: 28.10.2020 
pressure or heart rate, and does not stimulate histamine release (3). Therefore, it is suitable for patients with severe cardiovascular complications and life-threatening hypercortisolemia. However, to our knowledge, there is only one reported case of etomidate administration in infants with CS. We report the case of a 2-month-old girl presenting with hypertrophic cardiomyopathy (HCMP) and $\mathrm{CS}$, resulting from severe hypercortisolemia due to adrenocortical carcinoma (ACC), that was not resolved through surgery. Our report focuses on the use of etomidate to treat this patient.

\section{Case Report}

A 2-month-old girl was referred to the Pediatric Endocrinology Department in Severance Children's Hospital, South Korea for evaluation of cushingoid features. She was a full-term baby of normal weight, with unremarkable pregnancy and maternal history. During a hospital visit for regular checkup and vaccinations, her vital signs showed hypertension and tachycardia. Two-dimensional echocardiography revealed HCMP (Figures 1, 2). She was admitted to the cardiology department.

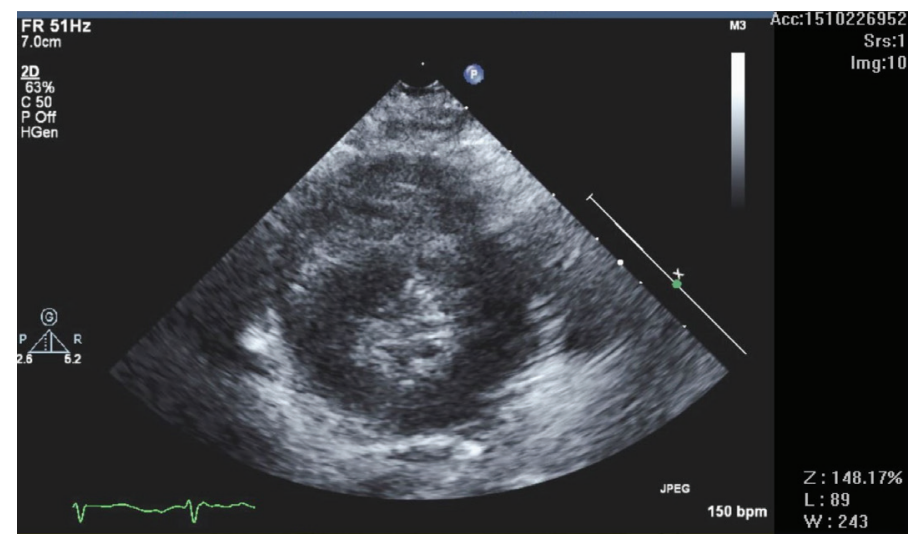

Figure 1. Parasternal short axis view of echocardiogram in infant patient with hypertrophic cardiomyopathy

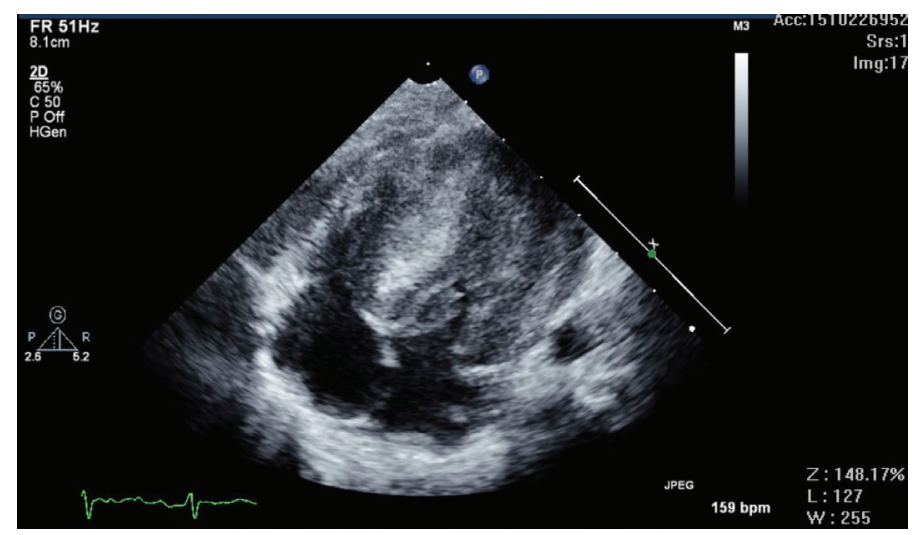

Figure 2. Four chamber view of echocardiogram in infant patient with hypertrophic cardiomyopathy
During her stay, she was referred to the endocrinology department due to cushingoid appearance, including a full moon face, purple striae, central obesity, and accumulation of fat in the abdomen, chest, and face. Her body weight, body length, and body mass index were $7.6 \mathrm{~kg}$ ( $>97^{\text {th }}$ percentile), $52 \mathrm{~cm}$ ( $<3^{\text {rd }}$ percentile), and $28.1 \mathrm{~kg} / \mathrm{m}^{2}\left(>97^{\text {th }}\right.$ percentile), respectively.

Basal cortisol and adrenocorticotropic hormone (ACTH) were assessed at $8 \mathrm{am}$, and the cortisol level was 112.7 $\mu \mathrm{g} / \mathrm{dL}$ (reference range 6.0-18.4 $\mu \mathrm{g} / \mathrm{dL}$ at 7-10 am) with a concomitant suppressed plasma ACTH level of $<1 \mathrm{pg} / \mathrm{mL}$ (reference range 7.2-63.3 pg/mL). Further diagnostic studies showed high 24-hour urinary free cortisol levels $(1,777.1$ $\mu \mathrm{g} /$ day and 2,782.7 $\mu \mathrm{g} /$ day, respectively, reference range 58.0-403.0 $\mu \mathrm{g} /$ day), and low ACTH level, consistent with ACTH-independent CS. Abdominal sonography revealed an approximately $4.5 \times 3.5 \times 4.7 \mathrm{~cm}$ heterogeneously hypoechoic lesion in the right suprarenal space, and several small enhancing lesions in the liver, suspected to be metastatic lesions. Resection of the adrenal gland tumor was performed and histopathologic examination confirmed ACC with poor prognosis according to the Wieneke-index criteria (4). The metastatic liver lesions were also removed, and metastasized ACC was histopathologically confirmed.

The patient's postoperative cortisol level immediately decreased to $22.6 \mu \mathrm{g} / \mathrm{dL}$, and we closely monitored her cortisol levels to prevent an adrenal crisis (data shown in Table 1). After 24 hours, cortisol levels stabilized at $15.9 \mu \mathrm{g} /$ $\mathrm{dL}$, but gradually increased 48 hours after surgery without steroid replacement. On postoperative day 18 , her cortisol level was $68.0 \mu \mathrm{g} / \mathrm{dL}$, and imaging studies revealed severe progressive cardiomegaly with compressed lungs and multiple liver metastases. Her general condition and vital signs then deteriorated, with hypertension (blood pressure, 170/100 mmHg) and tachycardia (heart rate, 140 beats/ minute). Therefore, medical treatment was considered instead of reoperation. First, the oncology department started chemotherapy for the liver metastases. The planned chemotherapy was cisplatin-etoposide-doxorubicin. In addition, etomidate was selected to treat severe hypercortisolemia because of the patient's severe HCMP, severe hypertension, and liver metastases. We initially administered a $0.3 \mathrm{mg} / \mathrm{kg}$ loading dose of etomidate for severe hypercortisolemia, and subsequently maintained a dose of $0.03 \mathrm{mg} / \mathrm{kg} /$ hour. Her cortisol level decreased to 32.3 $\mu \mathrm{g} / \mathrm{dL}$ after four hours, and to $21.7 \mu \mathrm{g} / \mathrm{dL}$ after eight hours of etomidate infusion. However, her blood pressure decreased, possibly due to relative adrenal insufficiency. Therefore, we stopped the infusion of etomidate. Furthermore, after khree days of cisplatin and etoposide treatment, the patient's 


\begin{tabular}{|c|c|c|c|c|c|c|}
\hline & \multicolumn{2}{|l|}{ Postoperative } & \multicolumn{2}{|c|}{$\begin{array}{l}\text { First attempt etomidate (loading } 0.3 \mathrm{mg} / \mathrm{kg} \text {, } \\
\text { infusion rate } 0.03 \mathrm{mg} / \mathrm{kg} / \text { hour) }\end{array}$} & \multicolumn{2}{|c|}{$\begin{array}{l}\text { Second attempt etomidate (infusion } \\
\text { rate } 0.03 \mathrm{mg} / \mathrm{kg} / \text { hour) }\end{array}$} \\
\hline & ACTH $(\mathrm{pg} / \mathrm{mL})$ & Cortisol ( $\mu \mathrm{g} / \mathrm{dL})$ & ACTH $(\mathrm{pg} / \mathrm{mL})$ & Cortisol ( $\mu \mathrm{g} / \mathrm{dL})$ & ACTH $(\mathrm{pg} / \mathrm{mL})$ & Cortisol ( $\mu \mathrm{g} / \mathrm{dL})$ \\
\hline Baseline & $<1.0$ & 107.8 & $<1.0$ & 63.3 & $<1.0$ & 80.2 \\
\hline 1 hour & 8.84 & 22.6 & & & & \\
\hline 3 hours & 4.46 & 19.8 & & & & \\
\hline 6 hours & & 17.6 & & & & \\
\hline 8 hours & & & & 21.7 & & 44.6 \\
\hline 12 hours & & 19.6 & & & & 30.6 \\
\hline 24 hours & $<1.0$ & 15.9 & & & & 38.5 \\
\hline 36 hours & & 19.5 & & & & 19.4 \\
\hline 7 days & $<1.0$ & 34.7 & & & & \\
\hline 8 days & & 33.3 & & & & \\
\hline 18 days & $<1.0$ & 68.0 & & & & \\
\hline
\end{tabular}

chest radiography revealed severe pneumonia and her oxygen saturation declined, probably due to suppression of the immune system. Thus, the patient's chemotherapy also had to be stopped.

Four days after stopping etomidate, her cortisol level increased to $80.2 \mu \mathrm{g} / \mathrm{dL}$ again, and we restarted etomidate infusion at a dose of $0.03 \mathrm{mg} / \mathrm{kg} /$ hour without a loading dose. Subsequently, her cortisol level decreased to $46.3 \mu \mathrm{g} /$ $\mathrm{dL}$ after four hours of etomidate infusion, and continued to slowly decrease, to reach $19.4 \mu \mathrm{g} / \mathrm{dL}$ at 36 hours. As the target cortisol level was 10-20 $\mu \mathrm{g} / \mathrm{dL}$ and her vital signs were stable, we maintained the etomidate dose at 0.03 $\mathrm{mg} / \mathrm{kg} /$ hour without glucocorticoid replacement (Table 1). However, blood tests showed pancytopenia (white blood cell $900 / \mu \mathrm{L}$, hemoglobin $8.3 \mathrm{~g} / \mathrm{dL}$, platelets $35,000 / \mu \mathrm{L}$ ) at six days after stopping chemotherapy, and her pneumonia was exacerbated, with an acute respiratory distress syndrome pattern. Even her severe cardiomegaly did not improve, compressing against her lungs on chest radiography. Her oxygen saturation and vital signs rapidly deteriorated and she finally expired at seven days after chemotherapy had been stopped and five days after the second treatment with etomidate.

\section{Discussion}

Although surgery is the first choice in CS, medication should be considered when surgical treatment is not possible. In our case, even after extended surgical resection, cortisol level increased again due to metastatic liver lesions. We therefore chose medical treatment considering her poorer condition. However, there are no specific medication guidelines for infants with CS. Of the available drugs, we chose etomidate for several reasons. First, oral medications were not suitable, due to the patient's feeding and breathing difficulties resulting from severe cardiomegaly that compressed both lungs. Second, ketoconazole was illadvised, due to increasing serum cortisol levels caused by metastasized ACC liver mass. Last, a drug for cardiovascular stability was indicated due to her general unstable condition as a result of severe HCMP and hypertension.

Etomidate is a member of the imidazole family, initially developed as an anti-fungal agent, but popularly used as an anesthetic due to its potent hypnotic activity and promotion of cardiovascular stability (3). However, it was also found to increase mortality by lowering serum cortisol levels (5). Etomidate inhibits $11 \beta$-hydroxylase, catalyzes cortisol and corticosterone production from deoxycortisol and deoxycorticosterone, respectively, and can quickly reduce serum cortisol levels within 12 hours (6). Since then, etomidate has been used as a medical treatment for CS.

Optimal etomidate doses and treatment intervals are uncertain because of inconsistent evidence. In adult patients with CS, cortisol levels were dramatically reduced within hours of receiving a $0.03 \mathrm{mg} / \mathrm{kg}$ bolus followed by a $0.03-0.1 \mathrm{mg} / \mathrm{kg} /$ hour dose (6). Preda et al (7) reviewed 43 case reports, including pediatric patients, 
and recommended low-dose etomidate intravenous infusion at $0.04-0.05 \mathrm{mg} / \mathrm{kg} /$ hour for partial and slow blocking, to prevent adrenal insufficiency. However, this review contained only three pediatric patients, without a consistent dose (6 year-old male, $0.03 \mathrm{mg} / \mathrm{kg} / \mathrm{hour}$, titrated to $0.08 \mathrm{mg} / \mathrm{kg} /$ hour; 14 year-old female, 3-3.5 $\mathrm{mg} /$ hour; 17 year-old female, $10 \mathrm{mg}$ bolus then $2.5 \mathrm{mg} /$ hour) $(8,9,10)$, and no infant patients. There is only one report about the use of etomidate in a 14-month old infant who received etomidate for five days at an infusion rate of $0.03 \mathrm{mg} / \mathrm{kg} / \mathrm{hour}$ (11). In our case, etomidate was administered as a 3 - $\mathrm{mg}(0.3 \mathrm{mg} / \mathrm{kg})$ bolus for induction and then as a continuous infusion at $0.03 \mathrm{mg} / \mathrm{kg} / \mathrm{hour}$. Serum cortisol levels began to drop after etomidate induction, and although the infusion rate was lower than previously described dosages $(6,7)$, the abrupt lowering of serum cortisol levels led to adrenal insufficiency, possibly due to a high loading dose. Lower etomidate dose may be needed in adrenal-origin CS because ACTH-independent CS is more sensitive than ACTH-dependent CS to adrenal enzyme blockade (7). Therefore, our second etomidate infusion was performed without a loading dose. Serum cortisol levels began to drop after four hours and slowly decreased to within normal range within 36 hours, accompanied by stable vital signs. In addition, her cortisol levels were stable for four days with the same dose of etomidate. Therefore, the doses used in this study (no bolus dose and infusion rate of $0.03 \mathrm{mg} / \mathrm{kg} /$ hour) may be appropriate for severe hypercortisolemia in infants.

The reported side effects of etomidate at anesthetic dose include myoclonic seizure, gastrointestinal issues, and dystonic reactions. Notably, our patient did not receive the anesthetic dose and experienced no adverse side effects. Therefore, we suggest that the described dose is safe and effective for infants. Although etomidate is relatively safe, an intensive care setting is recommended due to its sedative effect and the risk of inducing adrenal insufficiency (7). We also recommend monitoring serum cortisol (maintain between 10 and $20 \mu \mathrm{g} / \mathrm{dL}$ ) and potassium levels.

As etomidate has an anti-proliferative effects on adrenal cortical cells, it could be an anti-tumorigenic agent for metastatic ACCs (12). In addition, because cardiovascular complications are a major cause of morbidity and mortality for CS patients, etomidate is a good choice for patients with hypertension and HCMP from severe hypercortisolemia (3). Therefore, although this was, to our knowledge, the second attempt to treat an infant patient with CS using etomidate, we found that it was the best possible option after unsuccessful surgical treatment.

\section{Conclusion}

In conclusion, this is the youngest case, to our knowledge, of etomidate treatment in an infant patient with CS. After etomidate was administered to a 2-month-old infant with $\mathrm{CS}$ at a $0.03 \mathrm{mg} / \mathrm{kg} /$ hour infusion rate, her serum cortisol levels fell into normal range within 36 hours without any side effects.

\section{Ethics}

Informed Consent: A written informed consent was obtained from the patient's parents.

Peer-review: Externally peer-reviewed.

\section{Authorship Contributions}

Surgical and Medical Practices: Ahreum Kwon, Yongha Choi, Jo Won Jung, Concept: Ahreum Kwon, Design: HoSeong Kim, Ahreum Kwon, Data Collection or Processing: Yongha Choi, Analysis or Interpretation: Ahreum Kwon, Yongha Choi, Literature Search: Junghwan Suh, Yongha Choi, Ahreum Kwon, Writing: Ahreum Kwon, Yongha Choi. Ho-Seong Kim

Financial Disclosure: The authors declare that this study has received no financial support.

\section{References}

1. Alexandraki KI, Grossman AB. Therapeutic Strategies for the Treatment of Severe Cushing's Syndrome. Drugs 2016;76:447-458

2. Tritos NA, Biller BMK. Medical Therapy for Cushing's Syndrome in the Twenty-first Century. Endocrinol Metab Clin North Am 2018;47:427. 440. Epub 2018 Apr 9

3. Forman SA. Clinical and molecular pharmacology of etomidate Anesthesiology 2011;114:695-707

4. Wieneke JA, Thompson LD, Heffess CS. Adrenal cortical neoplasms in the pediatric population: a clinicopathologic and immunophenotypic analysis of 83 patients. Am J Surg Pathol 2003;27:867-881.

5. Watt I, Ledingham IM. Mortality amongst multiple trauma patients admitted to an intensive therapy unit. Anaesthesia 1984;39:973-981.

6. Schulte HM, Benker G, Reinwein D, Sippell WG, Allolio B. Infusion of low dose etomidate: correction of hypercortisolemia in patients with Cushing's syndrome and dose-response relationship in normal subjects. J Clin Endocrinol Metab 1990;70:1426-1430.

7. Preda VA, Sen J, Karavitaki N, Grossman AB. Etomidate in the management of hypercortisolaemia in Cushing's syndrome: a review. Eur J Endocrinol 2012;167:137-143. Epub 2005 Sep 27

8. Greening JE, Brain CE, Perry LA, Mushtaq I, Sales Marques J, Grossman AB, Savage MO. Efficient short-term control of hypercortisolaemia by low-dose etomidate in severe paediatric Cushing's disease. Horm Res 2005;64:140-143. Epub 2005 Sep 27

9. Chan LF, Vaidya M, Westphal B, Allgrove J, Martin L, Afshar F, Hindmarsh PC, Savage MO, Grossman AB, Storr HL. Use of intravenous etomidate to control acute psychosis induced by the hypercortisolaemia in severe paediatric Cushing's disease. Horm Res Paediatr 2011;75:441-446. Epub 2011 Mar 24 
10. Dabbagh A, Sa'adat N, Heidari Z. Etomidate infusion in the critical care setting for suppressing the acute phase of Cushing's syndrome. Anesth Analg 2009;108:238-239.

11. Yun Castilla C, Rodríguez Amuedo F, Morales Martínez A, López Siguero JP, Martínez Aedo MJ, Milano Manso G. Usefulness of ethomidate in patients with Cushing syndrome with severe arterial hypertension and hypopotassemia. Med Intensiva 2017;41:321-322. Epub 2016 Jul 22
12. Hahner S, Stürmer A, Fassnacht M, Hartmann RW, Schewe K, Cochran S, Zink M, Schirbel A, Allolio B. Etomidate unmasks intraadrenal regulation of steroidogenesis and proliferation in adrenal cortical cell lines. Horm Metab Res 2010;42:528-534. Epub 2010 Mar 29 